\title{
Scientific Research on Bronze Ware from Western Zhou Dynasty to Spring and Autumn Period Unearthed in Jilin Da'an Hou-taomuga Site
}

\author{
Han Liu, Yanxiang Li, Lixin Wang \\ University of Science \& Technology Beijing, USTB
}

Keywords: Jilin, hou-taomuga site, baijinbao culture, bronze, scientific analysis.

\begin{abstract}
This paper utilizes microscopic observation, optical microscopic, SEM-EDS to analyze 9 bronze artifacts which were excavated from the tomb of Hou-taomuga Site, a Baijinbao culture in Dagan, Jilin Province. Combined with their unearthed information, it can be sure that the people had started to use bronze of copper-arsenic in this area during this period. The decorations of 8 bronze artifacts might be produced by the same mound, and some objects might be casted together. Their composition was stable, so these bronze might be made up of copper and arsenic antimony lead intergrowth ore smelting. Also, they might be arsenic containing antimony and lead ore collocation with copper ore smelting production.
\end{abstract}

\section{Culture Background Of Hou-Taomuga Site}

Hou-taomuga site is located in rolling hill on the east bank of Xinhuangpao, Honggangzi Township, Dagan, and Jilin. The geographic coordinates are northern latitude $45^{\circ} 39^{\prime} 27.5^{\prime \prime}$ and east longitude $123^{\circ} 47^{\prime} 15.1^{\prime \prime}$, it is 130-155 meters above sea level [1]. Numerous remains of seven different cultural periods from the Neolithic Age to Liao and Jin Dynasties have been recognized at present after continuous excavations from 2011 to 2014[2].

Bronze ware is unearthed from cultural relics in the site since the fifth period (the ware belongs to Baijinbao Culture, the period is roughly the same as Western Zhou Dynasty to spring and Autumn Period). However, the number of the unearthed bronze ware is small. Most bronze wares were unearthed from the sixth period (they belong to the second period culture of Han Dynasty, which is roughly the same as the Warring States Period to the Western Han Dynasty). 9 bronze wares unearthed from the fifth period are analyzed and explained only in the paper.

\section{Simple Introduction of Unearthed Bronze Ware}

There are few relics left in the 5th period in Hou-taomuga site. Only 3 tombs were discovered, which all belong to pit tombs. 9 bronze wares were unearthed from relics left in the period, including 8 pieces of Passementerie and 1 piece of copper tool. 9 bronze wares were unearthed from a III area M7. 8 pieces of Passementerie belong to accessories. They were worn on the front area of the owner of the tomb. The copper tool was found on the arm of the right hand of the owner of the tomb. It is a household tool, the back of the tool is convex, and the tip of the tool is slightly upward.

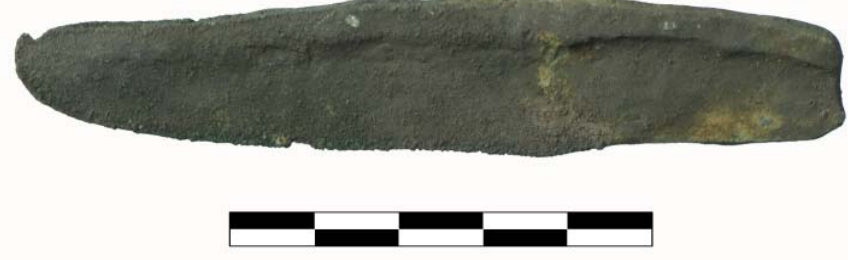

Figure 1. AIIIM7: 7 copper tool 


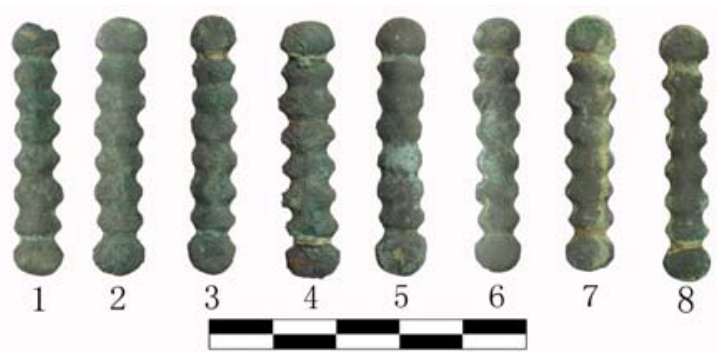

Figure 2. Passementerie (1.AIIIM7: 1 2. AIIIM7: 2 3. AIIIM7: 3 4. AIIIM7: 4

5. AIIIM7: 5 6. AIIIM7: 6 7. AIIIM7: 10 8.AIIIM7: 11)

(Experiment number and unearthing number are shown in Table 1)

\section{Metallographic Structure Observation}

Metallographic specimen was prepared in accordance with the conventional procedure: first, a suitable analysis section was selected aiming at one sample for sample mounting, the section was polished with sand paper and burnished with a polishing machine. Hydrochloric acid alcohol solution with concentration of 3\% was used as etching liquid for bronze ware finally according to material condition of the sample, thereby discovering the microstructure morphology of the sample. The metallographic microscopy systems used in the study include Leica DM4000M and Leica DMRXP microscopic image analysis system. The analysis results are shown as follows:

All 9 samples belong to cast histological alloy. A solid solution branch suffered from obvious dendritic segregation, and there were a small amount of grayish-green island $\gamma$ phases. The copper tool A275 had slight cold machining marks. The inclusion was slightly elongated and deformed. The remaining 8 samples of Passementerie had both a small number of grayish-green island-dependent $\gamma$ phases and inclusions such as sulfide, lead particles, etc.

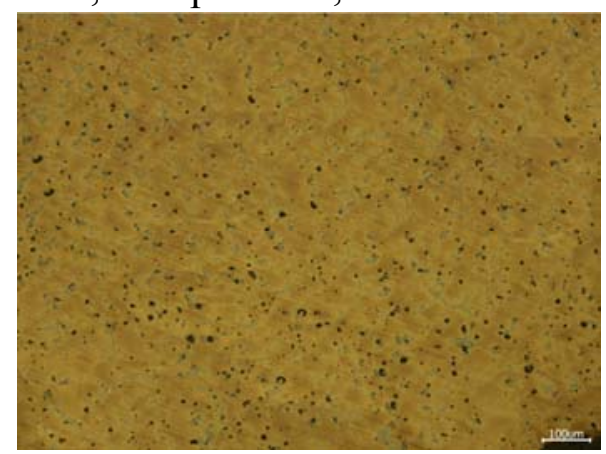

Figure 3. A274 metallographic structure

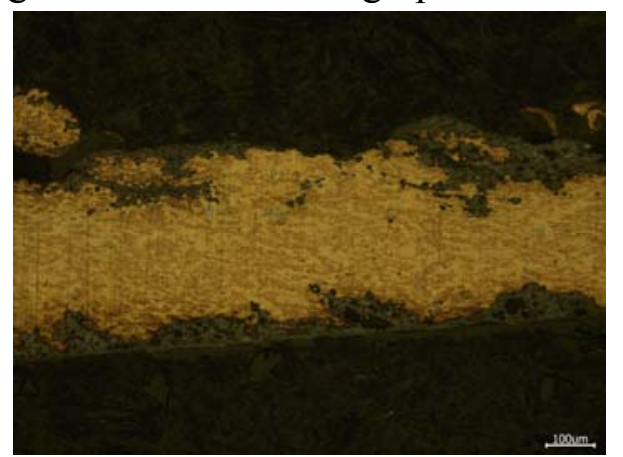

Figure 4. A275 metallographic structure picture

A solid solution branch suffered from obvious dendritic segregation in cast histological alloy. There were a small amount of gray-green island $\gamma$ phases, lead particles were spherically or massively distributed, and there were sulfide inclusions.

The cast histological alloy and the dendritic crystal segregation of Cupric Arsenio's $\alpha$ solid solution branch suffered from obvious dendritic segregation in cast histological alloy. There were a small amount of gray-green island $\gamma$ phases. 


\section{SEM-EDS Analysis}

The sample was worn and polished, which was then sprayed with carbon to conduct electricity. The sample was then placed into a scanning electron microscope for quantitative composition determination on samples. The scanning time of the surface was 60 seconds and the scanning time of the microregion was 30 seconds in composition detection. The average component analysis of the sample was generally determined in 3 different parts, and the average value of the sample was taken as the average component of the sample. The samples should be away from the rust area during scanning in order to ensure the relative accuracy of the experimental results. The JSM-6480LV scanning electron microscope of Japanese Electronics Company was used in the experiment. Nora System six energy dispersive spectrometer of Thermo Electron was equipped. The analysis results of SEM-EDS are shown in the Attached table 1(average composition).

Most samples had the characteristics of low arsenic content, low antimony content, low tin and low lead according to SEM-EDS analysis results. Only A275 belongs to copper tool, and the rest wares were Passementerie of the same shape from the perspective of analyzing ware type. The inclusion of A275 was slightly elongated and deformed from the perspective of analyzing back scattering images, and it was speculated that there were slight cold-processed traces. The remaining eight pieces of Passementerie showed no such traces. Average component analysis showed that: the ratio of elements in the other 8 samples was extremely similar except A275 (copper tool).

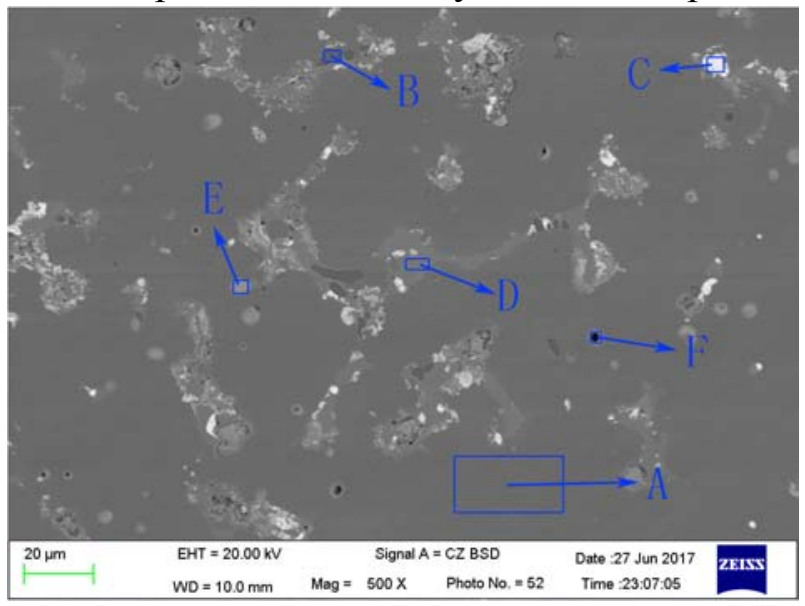

Figure 5. A274 back scattering picture

(A:Cu: 96.8\%, As: 3.2\%; B:Cu: 83.1\%, S: 16.9\%; C:Cu: 10.5\%, As: 1.2\%, Bi: 88.3\%; D:Cu: 67.3\%, As: 21.2\%, Sb: 4.7\%, Pb: 6.9\%; E:Sb: 67.4\%, As: 12.6\%, Cu: 7.5\%, Sn: 3.9\%, Bi: 8.6\%; F:Cu: $50.4 \%$, As: $6.8 \%$, Sb: $40.8 \%$, Sn: $2.0 \%$

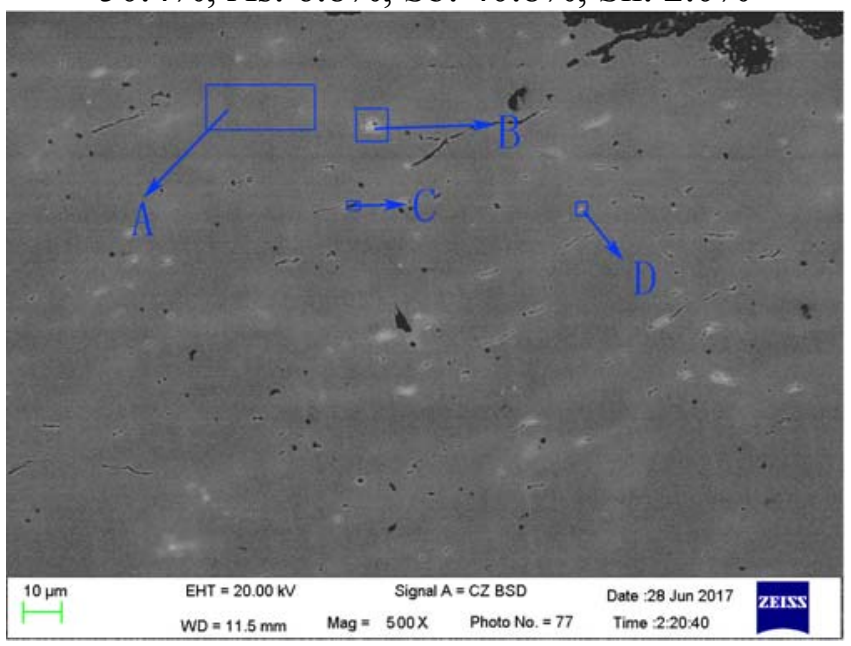

Figure 6. A275 back scattering picture

(A: $\mathrm{Cu}: 93.0 \%$, As: 7.0\%; B: Cu: 10.7\%, As: 41.3\%, Pb: 34.2\%, Sb: 7.1\%, Bi: 6.7\%; C: Cu: 73.7\%, As: $24.3 \%$, S: $2.0 \%$; D: Cu: $53.8 \%$, Ag: $35.1 \%$, As: $11.1 \%$ 
Arsenic-copper alloys appeared earlier in history according to existing studies. When the arsenic content was no more than $4-5 \%$, and the samples were more malleable, which had strong mechanical properties. When the arsenic content is between $5 \%$ and $8 \%$, ductility was reduced, and the mechanical properties were poor [3]. It is concluded that the mechanical performance of A275 was good, which conformed to the basic performance of copper tool. Passementerie was only used for daily wear, and the requirement on mechanical performance was not high as a result.

\section{Discussion}

\subsection{Alloy Composition and Production Technology.}

Existing research shows that a III zone M7 was in the fifth period of Hour - taomuga site. The relative era was about Western Zhou Dynasty to late spring and Autumn Period, and it belonged to late relic of Baijinbao Culture [4]. All 9 samples were cast microstructure alloys according to metallographic structure observation, and A275 had slight cold processing traces, which may be required for formation thereof. 8 pieces of Passementerie were made in the same way. Composition analysis of scanning electron microscopy showed that all 9 samples contained as, 8 pieces of Passementerie contained $\mathrm{Sb}$, it can be determined that arsenic copper alloy were used in the region since the period. It can be speculated that the batch of bronze ware may be smelted by $\mathrm{Cu}-\mathrm{As}-\mathrm{Sb}-$ Pub paragenic ore or arsenic-contained $\mathrm{Sb}$ and Pub, which were matched with copper ore for smelting together.

A total of 8 pieces of Passementerie were unearthed from the same tomb. The owner of the tomb was male and about 25 years old [4]. Passementerie was the same in shape production by the same manufacturing method, and the element proportion was similar. It was speculated that 8 pieces of Passementerie may be cast by the same type of mold. Although no earth stone model was unearthed in the site, stone models of Passementerie unearthed from other sites in the same period may be cast and shaped in the same batch [5].

\subsection{Lead Isotope Analysis.}

We carried out lead isotope ratio measurement on our bronze ware samples in order to discover the material source of 9 bronze wares. The lead isotope ratio data of samples in the study was obtained by Nuclear Industry Beijing Geological Research Institute according to GB/T17672-1999 'Determination method of lead, strontium isotope neodymium in rock 'through ISOPROBE-T thermal ionization mass spectrometer produced by British GV Company. The lead isotope measurement results of 9 bronze ware samples unearthed in M7 are shown in attached table 2.

The comparison result of lead isotope ratio showed that four samples of A270, A273, A274 and A277 had high degree of polymerization. Element composition ratio and characteristics of cast model unearthed in the same period were combined for speculating $d$ that the four objects may have the same or similar source of ore and may be made from the same batch through casting.

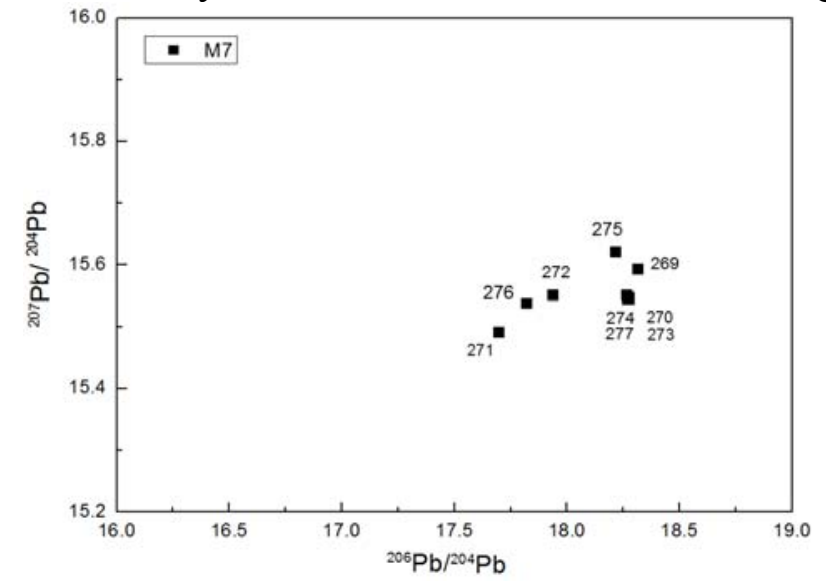

Figure 7. M7 bronze ware lead isotope Uranium lead picture 


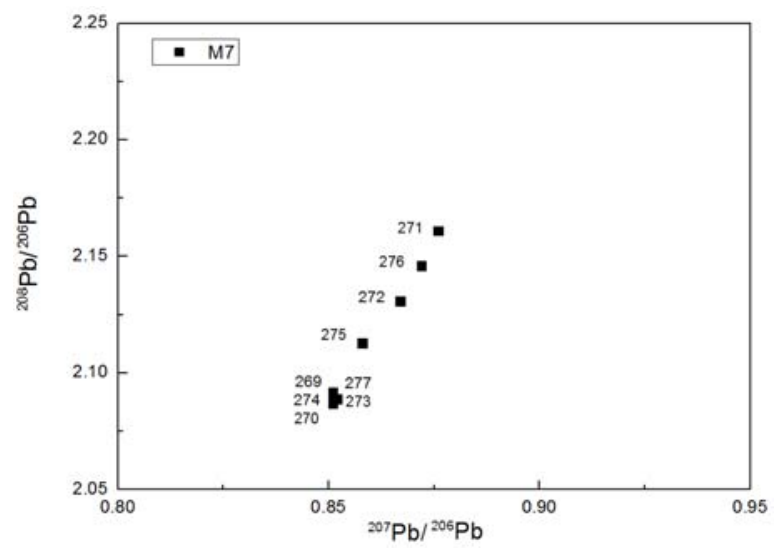

Figure 8. M7 bronze ware lead isotope thorium lead - uranium lead picture

The unearthed bronze wares of Baijinbao Culture mainly belonged to bronze wares underthed from the 3rd period relics in Baijinbao site at present [6]. The experimental results are combined for speculating that the bronze ware used by Baijinbao Culture is mainly arsenic-copper alloy. The conclusion will be further enriched with the discovery of more unearthed Baijinbao Culture bronze in the future.

When arsenic copper was not replaced by tin bronze, there were two reasons for the continued use of arsenic copper from the perspective of history development: firstly, the supply of tin was insufficient, and tin ore was not discovered [9]; secondly, smelting technology was limited. The reduction capacity was weak in the process of smelting, and a large amount of tin in slag was not reduced [10]. Slag analysis of several mining and smelting sites in the upper culture of Xijiadian in Western Liaoning was combined for speculating that Hou-taomuga site may also have weak reduction capability in smelting technology during the period.

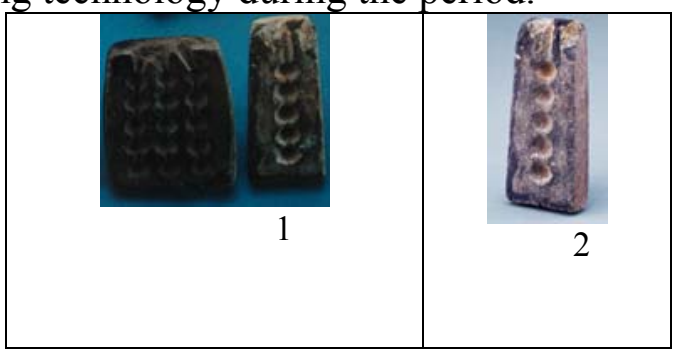

Figure 9 Pottery mound

(1. Pottery mound unearthed in Huangtuliang site of Ongniud Banner [7]; 2.Pottery mound collected from Shuangjing, Ningcheng, Inner Mongolia [8])

\section{Conclusion}

Metallographic structure observation and alloy composition measurement were carried out for 9 bronze wares unearthed in a Baijinbao Culture burial site of Da'an hou-taomuga site, Jilin Province. Comprehensive analysis of device unearthing information and archaeological typology was combined. It is believed that arsenic-copper alloy product was used since the period. 8 pieces of Passementerie among the bronze wares may be produced with the same mould, wherein a part of Passementerie may be cast in the same batch. Lead isotope data results show that some bronze wares may have the same or similar ore material sources. The alloy proportion of the whole batch of bronze wares is stable. It is speculated that the batch of bronze ware may be smelted by cu-as-sb-pb coprogenetic ore, or it may be smelted by arsenic-bearing ore containing $\mathrm{Sb}$ and $\mathrm{Pb}$, which was matched by copper ore for joint smelting.

Baijinbao Culture was discovered early in Sonnet Plain, which belonged to the first archaeological culture officially named in the area during Bronze Age. Bronze casting technology has been mastered in Baijinbao Culture according to the existing research. There was a certain scale of production. However, there are fewer bronze wares belonging to the culture in Sonnet plain green bronze wares 
unearthed at present. It is expected that the paper can provide further clues for scientific inquiry of Baijinbao Culture bronze wares.

Table 1. Alloy composition analysis of bronze ware unearthed in Hou-taomuga site AIIIM7

\begin{tabular}{|l|l|l|l|l|l|l|l|l|l|}
\hline Experiment number & Unearthing number & Ware type & $\mathrm{Cu}$ & $\mathrm{Sn}$ & $\mathrm{Pb}$ & $\mathrm{As}$ & $\mathrm{Ag}$ & $\mathrm{Sb}$ & $\mathrm{Bi}$ \\
\hline A269 & AIIIM7:1 & Passementerie (multiple) & 92.8 & 0.0 & 0.0 & 5.1 & 0.0 & 2.1 & 0.0 \\
\hline A270 & AIIIM7:2 & Passementerie (multiple) & 87.5 & 0.3 & 3.2 & 5.6 & 0.6 & 2.4 & 0.4 \\
\hline A271 & AIIIM7:3 & Passementerie (multiple) & 91.1 & 0.0 & 1.4 & 5.1 & 0.0 & 1.7 & 0.7 \\
\hline A272 & AIIIM7:4 & Passementerie (multiple) & 89.9 & 0.0 & 0.0 & 7.0 & 0.0 & 2.1 & 1.0 \\
\hline A273 & AIIIM7:5 & Passementerie (multiple) & 90.4 & 0.0 & 0.0 & 7.5 & 0.0 & 2.1 & 0.0 \\
\hline A274 & AIIIM7:6 & Passementerie (multiple) & 88.3 & 0.0 & 2.2 & 5.8 & 0.2 & 2.0 & 1.5 \\
\hline A275 & AIIIM7:7 & copper tool & 96.0 & 0.0 & 0.0 & 4.0 & 0.0 & 0.0 & 0.0 \\
\hline A276 & AIIIM7:10 & Passementerie (multiple) & 87.6 & 0.0 & 3.7 & 5.2 & 0.0 & 2.0 & 1.5 \\
\hline A277 & AIIIM7:11 & Passementerie (multiple) & 89.9 & 0.1 & 0.0 & 6.0 & 0.5 & 2.0 & 1.5 \\
\hline
\end{tabular}

Table 2. Lead isotope ratio analysis of bronze ware unearthed in Hou-taomuga siteAIIIM7

\begin{tabular}{|l|l|l|l|l|l|}
\hline Experiment number & ${ }^{206} \mathrm{~Pb} /{ }^{204} \mathrm{~Pb}$ & ${ }^{207} \mathrm{~Pb} /{ }^{204} \mathrm{~Pb}$ & ${ }^{208} \mathrm{~Pb} /{ }^{204} \mathrm{~Pb}$ & ${ }^{208} \mathrm{~Pb} /{ }^{206} \mathrm{~Pb}$ & ${ }^{207} \mathrm{~Pb} /{ }^{206} \mathrm{~Pb}$ \\
\hline A269 & 18.314 & 15.594 & 38.316 & 2.092 & 0.851 \\
\hline A270 & 18.275 & 15.545 & 38.136 & 2.087 & 0.851 \\
\hline A271 & 17.696 & 15.493 & 38.238 & 2.161 & 0.876 \\
\hline A272 & 17.937 & 15.552 & 38.219 & 2.131 & 0.867 \\
\hline A273 & 18.266 & 15.546 & 38.134 & 2.088 & 0.851 \\
\hline A274 & 18.275 & 15.548 & 38.142 & 2.087 & 0.851 \\
\hline A275 & 18.215 & 15.622 & 38.485 & 2.113 & 0.858 \\
\hline A276 & 17.820 & 15.539 & 38.247 & 2.146 & 0.872 \\
\hline A277 & 18.264 & 15.552 & 38.162 & 2.089 & 0.852 \\
\hline
\end{tabular}

\section{References}

[1]. Wang Lexan, Hue Dongfeng, Zhao Junkie, Liu Xiao, Site of Jilin Dagan Hou-taomuga New Stone Age / Chief Editor-State Administration of Cultural Heritage. China Important Archaeological Findings in 2012. Beijing: Cultural Relics Press, 2013.

[2]. Jilin University Frontier Archaeological Research Center, Jilin Institute of Archaeology. Jilin Da'an Hou-taomuga Site a Brief Report of Excavation, Archaeology, 2016(9)3-24.

[3]. Sun Shogun, Qian Wei. Overview of use of ancient copper, arsenic copper and bronze, The Second International Academic Conference on History of Machinery Technology in China and Japan, 2000(11)252-260.

[4]. Xiao Xiaoping. Human Bone Study for Jilin Dagan Hou-taomuga Site. Jilin: Jilin University, 2014, 245.

[5]. Joint Editing by China Inner Mongolia Institute of Archaeology and South Korea Northeast Asia Historical Consortium. Xiajiadian Bronze Ware of Upper Culture. South Korea: Northeast Asia Historical Consortium 2007, 04.391-393.

[6]. Heilongjiang Institute of Archaeology, Jilin University Archaeology Department. ZhaoyuanBaijinbao - revelation of a bronze era site at lower reaches of Nanjing River. Beijing: Science Press. 273-276.

[7]. Chen Hua. Goods-building Art of Bronze Era in China North Prairie under Culture Consideration. Art Journal, 2016(09)109. 
[8]. Joint editing by China Inner Mongolia Institute of Archaeology and South Korea Northeast Asia Historical Consortium. Xiajiadian bronze ware of upper structure. South Korea: Northeast Asia Historical Consortium 2007, 04.391-393.

[9]. Sun Shogun, Qian Wei. Overview of use of ancient copper, arsenic copper and bronze. The Second International Academic Conference on History of Machinery Technology in China and Japan, 2000(11)242.

[10]. Dong Liwung. Investigation and research on Xiajiadian upper culture mining and metallurgy site. Beijing: University of Science and Technology Beijing, 2012, 100. 